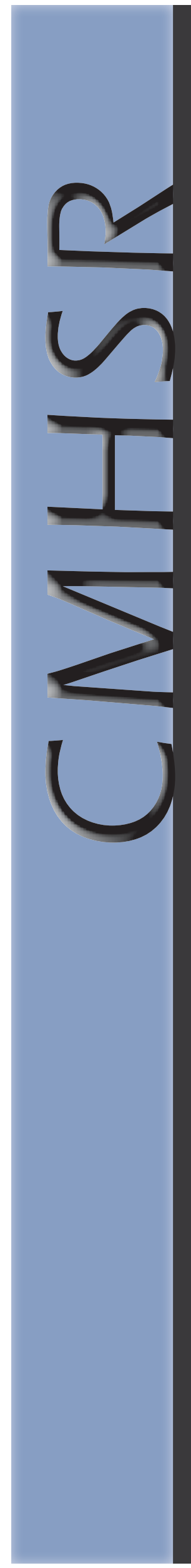

February 2010

Center for Mental Health Services Research

Vol 7, Issue 1

University of Massachusetts Medical School

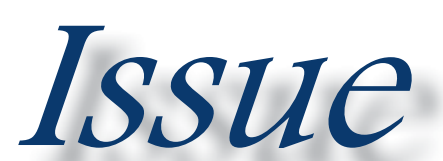

Brief

A Jail Diversion Program for Veterans with Co-occurring Disorders: MISSION - DIRECT VET*1

Paul P. Christopher, MD

$\mathrm{F}$ rom October 2001 through November 2007, approximately 1.6 million military service men and women were deployed to Iraq and Afghanistan in Operation Enduring Freedom/ Operation Iraqi Freedom (OEF/OIF), with one-third having more than one tour of duty (Congressional Research Service, 2008). An estimated 18.5\% of veterans returning from Iraq and Afghanistan have an active mental health condition, $14 \%$ have Post Traumatic Stress Disorder (PTSD) (Tantielian \& Jaycox, Eds, 2008), and over half have two or more mental health diagnoses (Seal, et. al, 2007). Problematic alcohol use among returning veterans is approximately 25\%, significantly higher than pre-deployment levels (Hoge, et. al, 2004). Diagnoses of alcohol use disorders increased from $1.1 \%$ to $7.1 \%$, and drug use disorders increased from $0.2 \%$ to $3.0 \%$ among veterans from 2002 to 2008 (Seal, et. al, 2009). Despite the high rate of mental health symptoms and problematic substance use among veterans, fewer than half seek care for these concerns (Hoge, et. al, 2004).

Given the rates of co-occuring disorders among returning OEF/OIF service personnel, there has been a growing concern about the risk of their becoming involved in the criminal justice system upon return. These concerns stem from a recognition of a high risk for incarceration among nonveteran individuals with co-occurring mental illness and substance use disorders (Bureau of Justice Statistics, 2006) and the increase in incarceration of veterans following the Vietnam War (Walker, 1981). There has been a national movement toward developing diversion strategies to intercept veterans with mental health conditions at multiple points in the criminal justice process (CMHS National GAINS Center, 2008).

Through a grant from the Substance Abuse and Mental Health Services Administration (SAMHSA), the Massachusetts Department of Mental Health $(\mathrm{DMH})$, in partnership with investigators at the University of Massachusetts Medical School (UMMS) and the Veterans Administration (VA), along with numerous state agencies, has developed a court based jail diversion program with priority to veterans: MISSION DIRECT VET (MDV).* This brief describes this initiative.

(C) 2009 Center for Mental Health Senvices Research Department of Psychiatry

University of Massachusetts Medical School

\section{Goals of MISSION-DIRECT VET}

- Identify criminal defendants who are veterans with mental illness and substance use disorders prior to the sentencing of their criminal case

- Propose services and treatment options as alternatives to incarceration

- Coordinate services between treatment providers and the courts, attorneys, jails, probation officers, and houses of correction

\section{Intervention Design}

Representatives from state and local mental health, criminal justice, public health, and veterans agencies met regularly during the first year to collaborate in designing the diversion strategy, identifying potential barriers, and working toward acceptable solutions. The resulting model is a court based diversion program designed to divert individuals at the post-adjudication stage of criminal justice involvement. (Figure 1). Inclusion criteria are: $>18$ years old, veteran status, trauma history or other Axis I psychiatric disorder, and substance abuse or dependence, with criminal charge(s).

Eligible defendants will be informed of the program either by their attorney or through literature distributed by the court. Following eligibility determination, MDV personnel will conduct a clinical assessment and present a treatment plan to defense counsel who may in turn present the MDV option to the court for consideration as an option in lieu of a sentence involving incarceration.

\footnotetext{
${ }^{1}$ Funding made possible via SAMHSA Grant (RFP SM-08-009) to the Department of Mental Health. Investigators: Debra A. Pinals, M.D., David Smelson, Psy.D., Carl Fulwiler, M.D., Ph.D, Stephanie Hartwell, Ph.D., William Fisher, Ph.D., Albert Grudzinskas, J.D., Mary Ellen Foti, M.D.

* MISSION DIRECT VET = Maintaining Independence and Sobriety through Systems Integration, Outreach, and Networking - Diversion \& Recovery for Traumatized Veterans
} 
Figure 1. Identification and diversion of defendants.

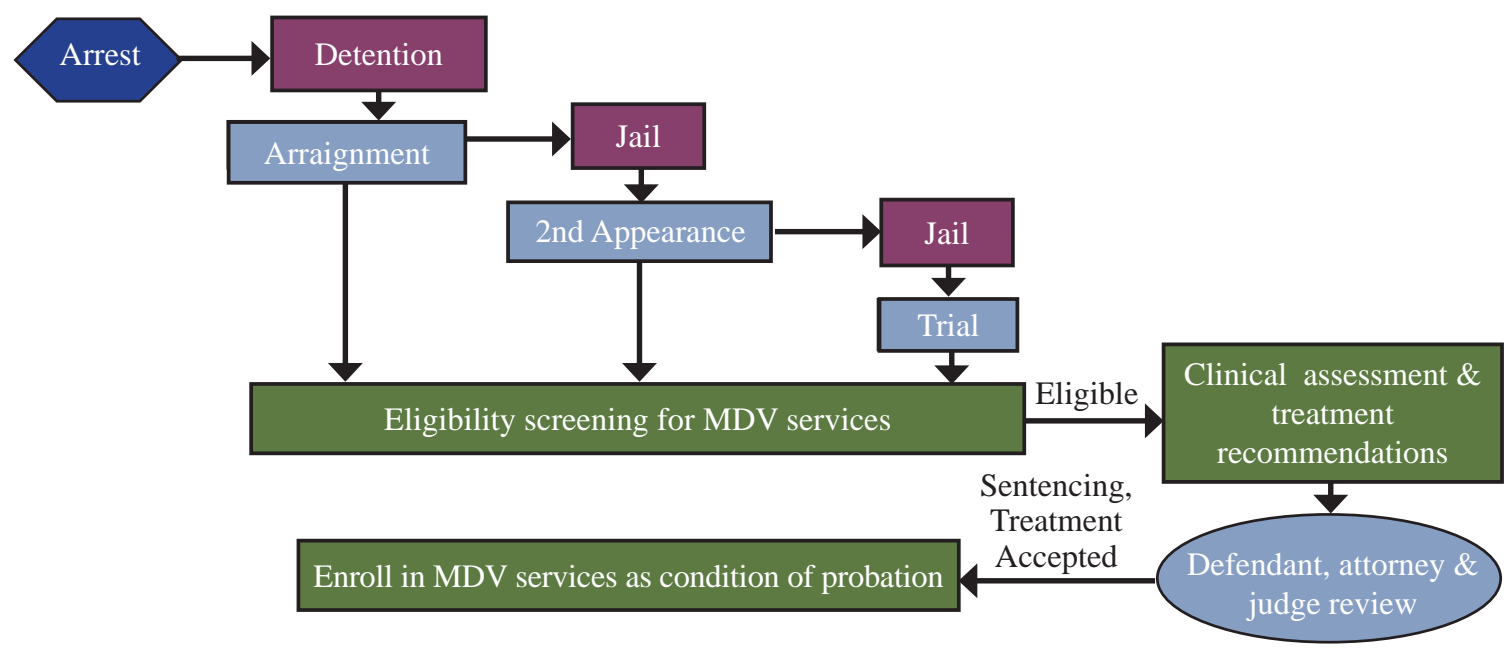

Criminal justice personnel and public defenders are receiving training on the mental health needs of returning veterans and on the MDV program. All personnel are receiving training in trauma-informed care.

\section{Services Design}

MDV participants will receive one year of Critical Time Intervention case management, (an intensive but time-limited intervention designed to promote engagement in services and supports available in the community), Dual Recovery Therapy (an approach to counseling people with co-occurring mental health and substance abuse disorders that involves teaching clients self-management skills and reinforcing them through follow-up), and peer support that incorporates role modeling of recovery behaviors and reinforces the need for treatment engagement. The program is designed to ensure veterans receive wraparound services including:

Mental health and substance abuse treatment, including trauma informed care:

- 12 months of peer support

- 12 months case management

- Manualized MISSION approach (see below)

Referrals and linkages to services as needed including:

- Medical and mental health care

- Substance abuse treatment

- Veterans services

- Vocational and independent living skills programs

- Transitional residence programs

- Family support
Coordination of care between local, state, and probation and parole agencies, to ensure seamless services and support to veterans.

Services are based on a care coordination approach and the SAMHSA-funded MISSION model developed for homeless veterans, (Kussman, 2009; Smelson, et. al, 2007). Modifications include integrating trauma-informed care through consultation with the VA National Center for PTSD along with a new emphasis on preventing legal system involvement. Program products will include an improved statewide DMH/VA/UMMS network and a new trauma-sensitive, veteran-focused treatment manual and consumer workbook usable in settings across the nation. MDV began accepting referrals for the pilot phase from Worcester District Court in November 2009. Evaluation of the pilot phase will be used to make adjustments to the program before expanding to additional sites the following year. A subsequent large-scale evaluation of mental health, substance abuse and criminal justice outcomes will be completed at the end of the 5-year project.

Future program concerns will be discussed in ongoing advisory meetings with stakeholders. One of MDV's goals is to develop a sustainable infrastructure for diversion and treatment services by blending funding from different agencies, reorganizing existing funds, exploring new sources of federal, local and private funding.

Visit us on-line at www.umassmed.edu/cmhsr

View Bibliography on-line at www.umassmed.edu/uploadedFiles/ cmhsr/Publications/bibliographies/Brief45.pdf 